\title{
Study of Anti-Inflammatory Activity of FatsiphloginumTM (Fatsia japonica) and a New Purified Triterpene-Rich Extract of Saponins (PS-551) in Experimental Model of Arthritis
}

\author{
L. TSIKLAURI ${ }^{2}$, F. DRAFI ${ }^{1}$, S. PONIŠT ${ }^{1}$, L. SLOVÁK ${ }^{1}$, M. CHRASTINA ${ }^{3}$, K. ŠVÍK ${ }^{1}$, \\ Z. KEMOKLIDZE ${ }^{2}$, E. KEMERTELIDZE ${ }^{2}$, K. BAUEROVÁ ${ }^{1}$
}

${ }^{1}$ Institute of Experimental Pharmacology and Toxicology, Centre of Experimental Medicine, Slovak Academy of Sciences, Bratislava, Slovak Republic, ${ }^{2}$ Iovel Kutateladze Pharmacochemistry Institute, Tbilisi State Medical University, Tbilisi, Georgia, ${ }^{3}$ Jessenius Faculty of Medicine in Martin, Comenius University, Slovak Republic

Received September 2, 2019

Accepted September 16, 2019

\section{Summary}

In this study, two extracts from Fatsia japonica-Fatsiphloginum ${ }^{\mathrm{TM}}$ (extract of triterpene glycosides containing $45-50 \%$ of fatsiosides (FS)) and purified triterpene-rich extract of saponins with code name PS-551 (PS) were administered in combination with methotrexate (MTX) and in monotherapy to rats suffering adjuvant arthritis (AA). The anti-inflammatory activities of extracts were evaluated as monotherapies in comparison with untreated AA. PS administered in higher dose showed on day 28 effective decrease of hind paw volume (HPV), decreased activity of gamma-glutamyl transferase (GGT) in joints, and also interleukin-17A was decreased significantly on day 14 . The higher dose of PS was more effective than both doses of FS. Further, we evaluated the higher doses of PS and FS in combination with MTX. PS improved the effect of MTX in combination more effective than FS (HPV, body weight and activity of GGT in joint). However, FS was more effective in reducing the level of IL-17A on day 14 and activity of GGT in spleen than PS. In conclusion, our study showed that generally FS has higher anti-arthritic activity comparing to PS. Thus, the novel combination of Fatsiphloginum $^{\mathrm{TM}}$ and methotrexate could be interesting for future clinical studies in patients suffering auto-immune diseases.

\section{Key words}

Arthritis • Methotrexate • Saponins • Terpenes • Fatsia japonica

\section{Corresponding author}

K. Bauerova, Institute of Experimental Pharmacology and Toxicology, Centre of Experimental Medicine, Slovak Academy of
Sciences, Dúbravská cesta 9, Bratislava, Slovak Republic. E-mail: katarina.bauerova@savba.sk

\section{Introduction}

Rheumatoid arthritis (RA) is an autoimmune disease manifested as chronic, progressive and invasive arthritis. It is characterized by synovial hyperplasia, inflammation, destruction of articular tissues and restricted movement of the joints (Fournier 2005). The pathogenesis of RA has not been fully understood yet. It has been suggested that the abnormal activation of inflammatory signaling pathways (Sglunda et al. 2014) and subsequently excessive oxidative stress play a critical role in the development of RA (Chen et al. 2017).

To control inflammatory symptoms and pain, disease modifying antirheumatic drugs are used; they are associated with certain undesirable side effects. Many clinical studies show that combination therapy is usually more effective than a single medicine alone (monotherapy) to control the inflammation in RA. A popular combination for relieving symptoms and preventing long-term joint damage and disability of arthritis is methotrexate - major immunosuppressive substance and anti-inflammatory compound (Smolen et al. 2010, Hazlewood et al. 2016, Koziolová et al. 2018).

Herbal anti-inflammatory substances allocate a wide-raging mechanism of action including interaction 
with the inflammatory cascade, cytokine production, increased anti-oxidative effectiveness and other still unspecified effects that may contribute to joint protective effects (Maroon et al. 2010).

Triterpenoid glycosides (triterpenes) belong to the group of saponins, widely distributed in the plant kingdom and contain a large number of biologically active components. These compounds consist of a hydrophobic part, called aglycone, which is linked to one or several sugar chains that build the hydrophilic part of the molecule. Because of their amphiphilic nature, saponins possess also surface-active properties and are able to efficiently solubilize hydrophobic molecules (Wu et al. 2014, Mesgarzadeh et al. 2017, Walthelm et al. 2001).

It has been proven that triterpenes are characterized by a wide spectrum of pharmacological activities, including anti-arthritic and anti-inflammatory actions (Sultana and Saify 2012). These effects have been described as a result of mediators of inflammation inhibition with its antioxidant property to suppress the formation of reactive oxygen species (ROS) which also play a major role in inflammation (Desai et al. 2010, Wang et al. 2008, Sparg et al. 2004).

Fatsia japonica (Thunb.) Decne et Planch. (Araliaceae) is an evergreen plant growing in the regions around Black Sea. At the Institute of Pharmacochemistry, Tbilisi State Medical University (TSMU) in the Laboratory of Terpene Compounds ethanolic extract of the leaves of Fatsia japonica (formulated into paramedical preparation - Fatsiphloginum ${ }^{\mathrm{TM}}$ ) was obtained. Five triterpene glycosides (fatsiosides) were also identified in the ethanolic extract of leaves of Fatsia japonica. The original para-medical preparation Fatsiphloginum $^{\mathrm{TM}}$ is available as $25 \mathrm{mg}$ and $50 \mathrm{mg}$, coated tablets. The active substance of Fatsiphloginum ${ }^{\mathrm{TM}}$ possesses anti-rheumatic, anti-inflammatory and analgesic activities and it is an original, nonsteroidal para-medical preparation used in Georgia (Getia et al. 2017). The active substance of Fatsiphloginum ${ }^{\mathrm{TM}}$ is hygroscopic dry powder which represents the crude extract of triterpene glycosides containing $45-50 \%$ of fatsiosides (FS) - derivatives of hederagenin and oleanic acid (Kemertelidze et al. 2001, Shalamberidze et al. 1998, Tsiklauri et al. 2004). The Laboratory of Terpene Compounds of TSMU has continued in the research of this ethanolic extract and recently more purified triterpene-rich extract of saponins with code name PS-551 (PS) was obtained from Fatsia japonica. This extract - PS-551 is non-hygroscopic dry powder and contain oleanic fatsiosides.

The aim of this study was to evaluate the antiinflammatory activity of orally administrated herbal preparation with code name PS-551 and compare it with the active substance, which is the main part of the original para-medical preparation Fatsiphloginum ${ }^{\mathrm{TM}}$. Moreover, the effect of combination of PS or FS with methotrexate on the adjuvant-induced arthritis (AA) progression was evaluated. For this purpose, the paw volume (HPV), change of body weight (CBW), arthritic score, along with biochemical and immunological markers in plasma and tissues were assessed.

\section{Methods}

\section{Drugs and chemicals}

The crude extract of triterpene glycosides, active substance of original drug - Fatsiphloginum ${ }^{\mathrm{TM}}(\mathrm{FS})$ - and purified triterpene-rich extract of saponins with code name PS-551 (PS) used in this experiment were prepared in the laboratory of Terpene Compounds of Kutateladze Pharmacochemistry Institute. The stock suspension of compounds tested was prepared on daily basis, as vehiculum aqua pro injectione was used (B. Braun Melsungen AG, Germany). Incomplete Freund's adjuvant was obtained from MERCK (Sigma Aldrich, Germany) and heat-inactivated Mycobacterium butyricum was obtained from Difco Lab (USA). Methotrexat (Ebewe ${ }^{\circledR}$ $20 \mathrm{mg} / \mathrm{ml}$ ), heparin (HEPARIN LÉČIVA ${ }^{\circledR} 50 \mathrm{~K}$ ) and anesthesia (Zoletil ${ }^{\circledR} 50$ and Xylariem ${ }^{\circledR} 20 \mathrm{mg} / \mathrm{ml}$ ) were obtained directly from public pharmacy. Chemicals for GGT: buffer $\left(2.6 \mathrm{mM} \mathrm{NaH} \mathrm{PO}_{4}, 50 \mathrm{mM} \mathrm{NaH} \mathrm{NO}_{4}\right.$, $15 \mathrm{mM}$ EDTA, $68 \mathrm{mM} \mathrm{NaCl}$; pH 8.1 ); $8.7 \mathrm{mM}$ $\gamma$-glutamyl-p-nitroaniline, $44 \mathrm{mM}$ methionine) $65 \%$ isopropylalcohol, methanol were obtained from MERCK (Sigma Aldrich, Germany). All chemicals were in pharmaceutical quality, purity and analytical grade.

\section{Animals}

In this experiment Male Lewis rats were used, weighing 160-180 g, obtained from the breeding station Dobrá Voda (Slovakia). Rats had free access to standard pelleted diet and tap water ad libitum. The animal facilities comply with the European Convention for the Protection of Vertebrate Animals Used for Experimental and Other Purposes. The experimental protocol was approved by the Ethics Committee of the Institute of Experimental Pharmacology and Toxicology and by the State Veterinary and Food Administration of the Slovak Republic. 
Induction of adjuvant arthritis (AA)

After 7-days quarantine, the animals were allocated to 9 groups of eight-ten rats in each group. Group one was used as healthy control. Group two were untreated AA rats. In group three to nine AA rats were treated as given in experimental design below (Table 1). Rat's adjuvant arthritis is an experimental model of inflammation with proven track record of predictability (Bendele 2001). Adjuvant arthritis was induced by means of intradermal injection at the base of the rat's tail, with $0.1 \mathrm{ml}$ suspension of $12 \mathrm{mg} / \mathrm{ml}$ heat-killed Mycobacterium butyricum (MB) suspended in incomplete Freund's adjuvant (Bauerova et al. 2011).

Table 1. Experimental design.

\begin{tabular}{|c|c|c|}
\hline Group & Treatment and active substance & Posology \\
\hline Group 1: Healthy controls (HC) & vehiculum & $0.5 \mathrm{ml}$ \\
\hline Group 2: AA untreated & vehiculum & $0.5 \mathrm{ml}$ \\
\hline Group 3: AA + treatment & methotrexate (MTX) & $0.3 \mathrm{mg} / \mathrm{kg}$ of b.w. \\
\hline Group 4: AA + treatment & PS-551 (PS5) & $5 \mathrm{mg} / \mathrm{kg}$ of b.w. \\
\hline Group 5: AA + treatment & PS-551 (PS50) & $50 \mathrm{mg} / \mathrm{kg}$ of b.w. \\
\hline Group 6: AA + treatment & PS50 + MTX & $50 \mathrm{mg} / \mathrm{kg}+0.3 \mathrm{mg} / \mathrm{kg}$ of b.w. \\
\hline Group 7: AA + treatment & ac. sub. of Fatsiphloginum ${ }^{\mathrm{TM}}$ (FS5) & $5 \mathrm{mg} / \mathrm{kg}$ of b.w. \\
\hline Group 8: AA + treatment & ac. sub. of Fatsiphloginum ${ }^{\mathrm{TM}}$ (FS50) & $50 \mathrm{mg} / \mathrm{kg}$ of b.w. \\
\hline Group 9: AA + treatment & ac. sub. of Fatsiphloginum ${ }^{\mathrm{TM}}(\mathrm{FS} 50)+\mathrm{MTX}$ & $50 \mathrm{mg} / \mathrm{kg}+0.3 \mathrm{mg} / \mathrm{kg}$ of b.w. \\
\hline
\end{tabular}

AA - adjuvant arthritis, MTX - methotrexate, b.w. - body weight.

Anti-rheumatic medicine MTX was administrated orally twice a week during 28 days; all substances tested were administered daily orally from day 1 to day 28. After all animals were sacrificed under deep anesthesia, heparinized blood for plasma preparation and tissues of spleen and hind paw joint were taken on day 28 . The plasma samples were stored at $-70{ }^{\circ} \mathrm{C}$ until biochemical and immunological analysis.

\section{Dose selection}

Two doses of $5 \mathrm{mg} / \mathrm{kg}$ and $50 \mathrm{mg} / \mathrm{kg}$ of body weight were selected based on preliminary studies (data not published) which have showed better response for doses above $5 \mathrm{mg} / \mathrm{kg}$ of body weight for antiinflammatory effect.

Clinical parameters - hind paw volume (HPV), body weight of animals and arthrogram

Hind paw volume (HPV) was calculated as the percentage increase of the hind paw of each animal, compared to the HPV measured of the beginning of the experiment. HPV was recorded on days 1, 14, 21 and 28 by means of an electronic water plethysmometer (UGO BASILE, Comerio-Varese, Italy). The body weight of the animals (g) was measured on days 1, 14, 21 and 28. The arthritic score was measured as the total score of HPV $(\mathrm{ml}$, max. points 8$)+$ paw diameter of forelimb $(\mathrm{mm}$, max. points 5) + diameter of scab, in the site of MB application, measured parallel to the spinal column (mm, max. points 5) for each animal. The more points, the more sever the inflammation was.

Activity of $\gamma$-glutamyl transferase (GGT) in spleen and hind paw joint tissue

The activity of cellular $\gamma$-glutamyltransferase (GGT) in hind paw joint and spleen tissue homogenates was measured at the end of the experiment (on day 28) by the method of Orlowski and Meister (1970) and modified by Ondrejickova et al. (1993). Samples were homogenized by UltraTurax TP 18/10 (Janke\&Kunkel, Germany) for $1 \mathrm{~min}$ at $0{ }^{\circ} \mathrm{C}$ in phosphate buffer $(2.6 \mathrm{mM}$ of $\mathrm{NaH}_{2} \mathrm{PO}_{4}, 50 \mathrm{mM}$ of $\mathrm{Na}_{2} \mathrm{HPO}_{4}, 15 \mathrm{mM}$ of EDTA, $68 \mathrm{mM}$ of NaCl; $\mathrm{pH} 8.1)$ at $1: 9(\mathrm{w} / \mathrm{v})$. Substrates $(8.7 \mathrm{mM}$ of $\gamma$-glutamyl-p-nitroaniline, $44 \mathrm{mM}$ of methionine) were added to $65 \%$ isopropylalcohol to final concentrations of $2.5 \mathrm{mM}$ and $12.6 \mathrm{mM}$, respectively. After incubation for $60 \mathrm{~min}$ at $37^{\circ} \mathrm{C}$, the reaction was stopped with $2.3 \mathrm{ml}$ of cold methanol and the tubes were centrifuged for $20 \mathrm{~min}$ at 5,000 rpm (Centrifuge Eppendorf). Absorbance of supernatant was measured on spectrophotometer 
Specord 40 (Jena, Germany) in a $0.5 \mathrm{~cm}$ cuvette at $406 \mathrm{~nm}$. Reaction mixtures in the absence of either substrate or acceptor were used as reference samples.

\section{Measurement of interleukin 17 A in plasma}

For the determination of interleukin 17A (IL-17A) concentrations level in plasma, an ELISA kit from eBioscience ${ }^{\circledR}$ (Waltham, MA, USA) was used. The assay procedures were applied as described in the product manuals. The results were calculated from the standard calibration curves based on internal standards.

\section{Statistical analyses}

The mean values and \pm SEM were calculated in each group for particular parameter. Statistical significance among treated groups, untreated AA group and $\mathrm{HC}$ group were tested using parametric Analysis of Variance (ANOVA). After posthoc Dunett test, significance designations were specified as follows: extremely significant $(* * * \mathrm{p}<0.001)$, highly significant $(* * \mathrm{p}<0.01)$, significant $(* \mathrm{p}<0.05)$, and not significant $(\mathrm{p}>0.05)$.

\section{Results}

\section{Change of the body weight (CBW)}

A significant decrease in change of the body weight on day 14, 21 and 28 was observed in AA group compared to HC animals (**p<0.01 AA vs. HC, Fig. 1). The AA group treated with MTX was observed as highly significant on day 14 and 21 compared to the untreated AA group $\left({ }^{++} p<0.01\right.$ AA-MTX vs. AA). This effect of MTX continued till the end of the experiment, but not significant. Groups administered with both active substances (PS and FS $5 \mathrm{mg} / \mathrm{kg}$ ) showed not significant change of the body weight on day 14, 21 and 28. We observed a non-significant increase in higher dose of both substances (PS and FS $50 \mathrm{mg} / \mathrm{kg}$ ) for this parameter when administered alone. Both substances also demonstrated the dose dependent trend on day 14 and 21. Highly significant result showed the combination of FS in a dose of $50 \mathrm{mg} / \mathrm{kg}$ and MTX on day $14 \quad\left({ }^{++} \mathrm{p}<0.01\right.$ AA-FS50+MTX vs. AA) and the combination of PS in a dose of $50 \mathrm{mg} / \mathrm{kg}$ and MTX $\left({ }^{+} \mathrm{p}<0.05\right.$ AA-PS50+MTX vs. AA, Fig. 1).

\section{Hind paw volume (HPV)}

Hind paw swelling reveals both inflammatory and arthritic alterations occurring in adjuvant arthritic rats. The results in Table 3 indicate that from day 14, 21 and $28 \mathrm{HPV}$ reached a highly significant value in untreated AA groups comparing to healthy controls $\left({ }^{* *} \mathrm{p}<0.01\right.$ AA vs. HC, Table 2). Therapy with MTX reduced swelling on all days monitored comparing to untreated AA group; on days 14 and 21 this effect was highly significant $\left({ }^{++} \mathrm{p}<0.01\right.$ AA-MTX vs. AA). At the end of the experiment, the effect of MTX alone decreased the HPV by $28.55 \%$ compared to untreated AA group. The combination of PS in a dose of $50 \mathrm{mg} / \mathrm{kg}$ and MTX showed highly significant decrease of HPV on day 14 and $21\left({ }^{++} \mathrm{p}<0.01\right.$ AA-PS50+MTX vs. AA) comparing to untreated AA animals and this similar effect was also observed on day 28. The highly significant effect of FS in the dose of $50 \mathrm{mg} / \mathrm{kg}$ and MTX was showed on day $14\left({ }^{++} \mathrm{p}<0.01\right.$ AA-FS50+MTX vs. AA, Table 2) comparing to untreated AA animals. However, this effect was not significant on days 21 and 28 .

\section{Arthritic score}

The untreated AA group showed highly significant manifestation in arthritic score on days 14, 21, and 28 by physical observation compared to healthy rats $(* * p<0.01$ AA vs. HC, Fig. 2). The AA group treated with MTX in comparison to untreated AA animals showed highly significant arthritic score decrease on day $14\left({ }^{++} \mathrm{p}<0.01\right.$ AA-MTX vs. AA). Similar effect of MTX was also observed on day 21 and 28 without significance. The application of PS and FS showed no differences comparing to untreated AA rats. When MTX was in combination with PS or FS in higher dose, the effect observed was highly significant on day 14 comparing to untreated AA rats $\left({ }^{++} \mathrm{p}<0.01\right.$ AA-PS50+MTX vs. AA; ${ }^{++} \mathrm{p}<0.001$ AA-FS50+MTX vs. AA). The combination of PS in higher dose and MTX was observed significant also on days 21 and 28 comparing to untreated AA rats $\left({ }^{+} \mathrm{p}<0.05\right.$ AA-PS50+MTX vs. AA, Fig. 2).

Activity of $\gamma$-glutamyl transferase in joint and spleen tissue

The increased activity of GGT was highly significant in joint tissues and also in spleen observed in an untreated AA group; this activity was approximately 1.46 times higher comparing to the healthy controls in the joint $(* * \mathrm{p}<0.01 \mathrm{AA}$ vs. HC, Table 3$)$ and 3.60 higher in the spleen $(* * p<0.01$ AA vs. HC). Application of MTX led to decreased activity of GGT in the joint and spleen 


\section{Change of body weight}

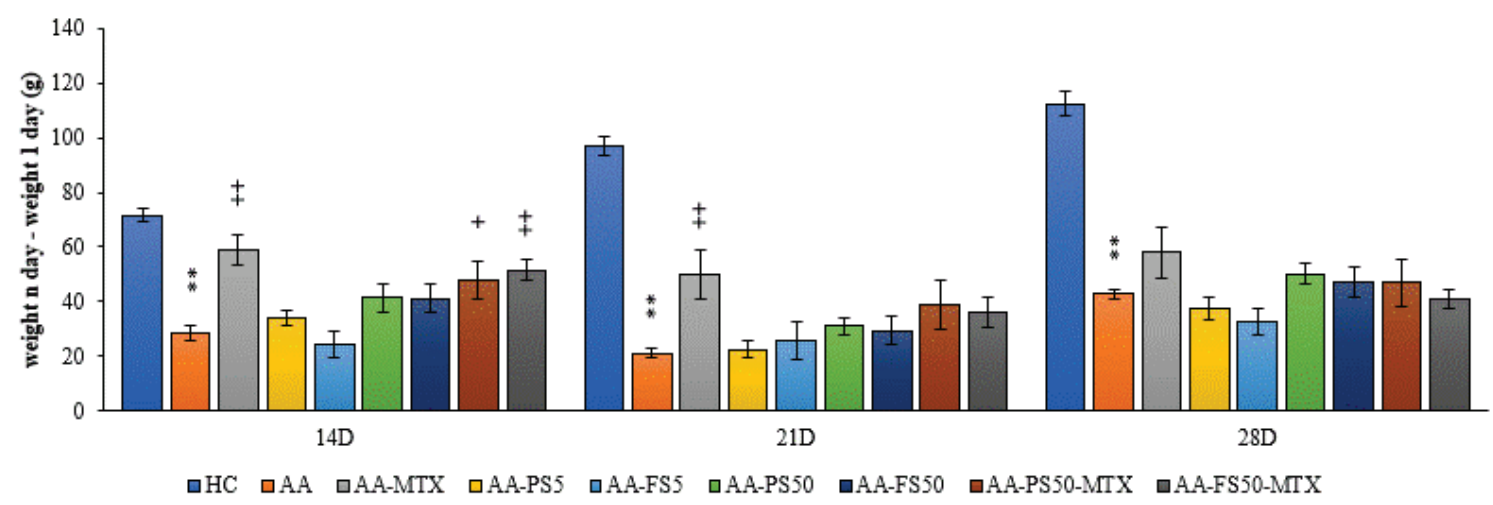

Fig. 1. Effect of PS, FS and MTX administered alone or in combination on change of the body weight on experimental day 14,21 and 28. $\mathrm{HC}$ - control group, AA - adjuvant arthritis group, AA-MTX - adjuvant arthritis group administered Methotrexate $0.3 \mathrm{mg} / \mathrm{kg}$ twice a week, AA-PS5/AA-FS5 - adjuvant arthritis group administered PS/FS at dose of $5 \mathrm{mg} / \mathrm{kg}$, AA-PS50/AA-FS50 - adjuvant arthritis group administered PS/FS at dose of $50 \mathrm{mg} / \mathrm{kg}$, AA-PS50+MTX and AA-FS50+MTX - adjuvant arthritis group administered PS or FS $(50 \mathrm{mg} / \mathrm{kg}$ ) and Methotrexate $0.3 \mathrm{mg} / \mathrm{kg}$ twice a week. Results are expressed as mean $\pm \mathrm{SEM}, \mathrm{n}=8-10$. Significant difference: $* * \mathrm{p}<0.01$ vs. $\mathrm{HC}_{1}{ }^{++} \mathrm{p}<0.01$ vs. $\mathrm{AA},{ }^{+} \mathrm{p}<0.05$ vs. $\mathrm{AA}$.

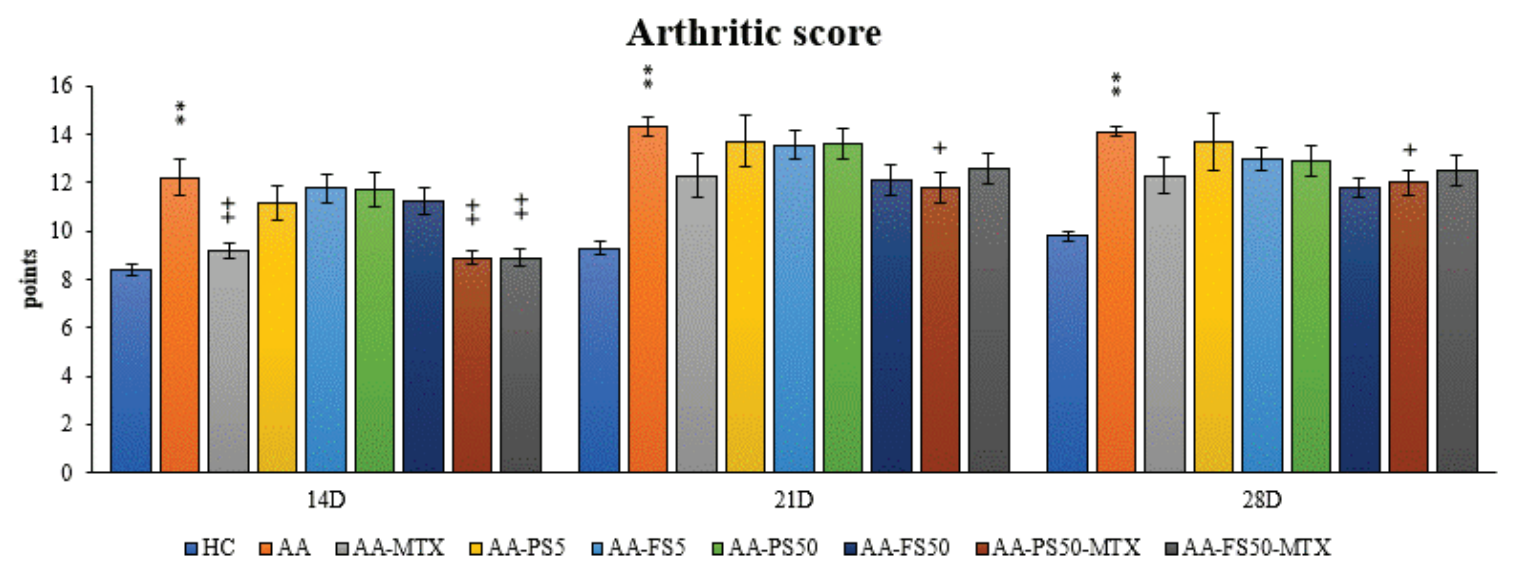

Fig. 2. Arthritic score in the model of adjuvant arthritis treated with PS, FS and MTX administered alone or in combination on the experimental day 14, 21 and 28. HC - control group, AA - adjuvant arthritis group, AA-MTX - adjuvant arthritis group administered Methotrexate $0.3 \mathrm{mg} / \mathrm{kg}$ twice a week, AA-PS5/AA-FS5 - adjuvant arthritis group administered PS/FS at dose of $5 \mathrm{mg} / \mathrm{kg}$, AA-PS50/ AA-FS50 - adjuvant arthritis group administered PS/FS at dose of $50 \mathrm{mg} / \mathrm{kg}$, AA-PS50+MTX and AA-FS50+MTX - adjuvant arthritis group administered PS or FS $(50 \mathrm{mg} / \mathrm{kg})$ and Methotrexate $0.3 \mathrm{mg} / \mathrm{kg}$ twice a week. Results are expressed as mean $\pm \mathrm{SEM}, \mathrm{n}=8-10$. Significant difference: ${ }^{* *} \mathrm{p}<0.01$ vs. $\mathrm{HC},{ }^{++} \mathrm{p}<0.01$ vs. $\mathrm{AA},{ }^{+} \mathrm{p}<0.05$ vs. AA.

\section{Levels of IL-17A in plasma}

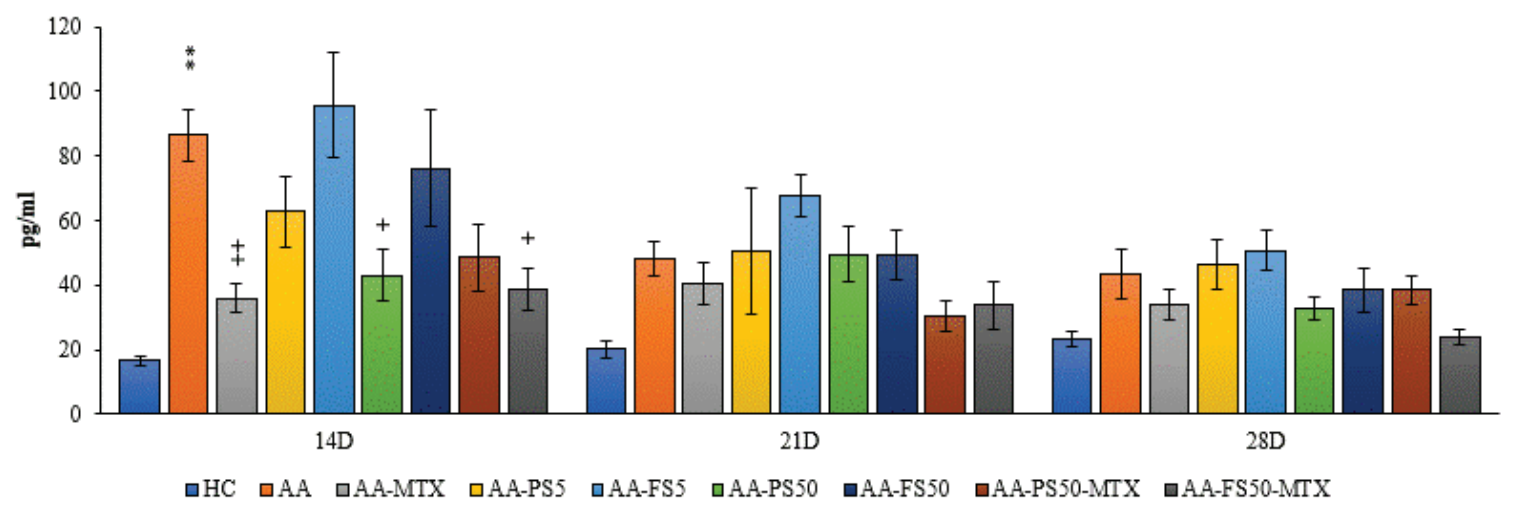

Fig. 3. Effect of PS, FS and MTX administered alone or in combination on the levels of IL-17A in plasma on experimental days 14,21 and 28. $\mathrm{HC}$ - control group, AA - adjuvant arthritis group, AA-MTX - adjuvant arthritis group administered Methotrexate $0.3 \mathrm{mg} / \mathrm{kg}$ twice a week, AA-PS5/AA-FS5 - adjuvant arthritis group administered PS/FS at dose of $5 \mathrm{mg} / \mathrm{kg}$, AA-PS50/AA-FS50 - adjuvant arthritis group administered PS/FS at dose of $50 \mathrm{mg} / \mathrm{kg}$, AA-PS50+MTX and AA-FS50+MTX - adjuvant arthritis group administered PS or FS $(50 \mathrm{mg} / \mathrm{kg})$ and Methotrexate $0.3 \mathrm{mg} / \mathrm{kg}$ twice a week. Results are expressed as mean $\pm \mathrm{SEM}, \mathrm{n}=8-10$. Significant difference: $* * \mathrm{p}<0.01$ vs. $\mathrm{HC},{ }^{++} \mathrm{p}<0.01$ vs. $\mathrm{AA},{ }^{+} \mathrm{p}<0.05$ vs. $\mathrm{AA}$. 
Table 2. Effect of PS, FS and MTX administered alone or in combination on HPV on experimental day 14, 21 and 28.

\begin{tabular}{|c|c|c|c|c|}
\hline \multirow{2}{*}{ Groups } & \multirow{2}{*}{ Treatment } & \multicolumn{3}{|c|}{ Change of hind paw volume (HPV) [\%] } \\
\hline & & Day 14 & Day 21 & Day 28 \\
\hline 1 & $H C$ & $9.80 \pm 1.10$ & $15.46 \pm 0.77$ & $20.12 \pm 0.88$ \\
\hline 2 & $A A$ & $48.10 \pm 7.62 * *$ & $65.71 \pm 3.55^{* *}$ & $61.12 \pm 2.13^{* *}$ \\
\hline 3 & $A A-M T X$ & $16.27 \pm 3.04^{++}$ & $42.95 \pm 8.47^{++}$ & $43.67 \pm 6.53$ \\
\hline 4 & $A A-P S 5$ & $44.58 \pm 7.68$ & $67.53 \pm 8.12$ & $59.48 \pm 13.26$ \\
\hline 5 & $A A-F S 5$ & $38.24 \pm 6.24$ & $60.44 \pm 4.75$ & $45.37 \pm 3.49$ \\
\hline 6 & $A A-P S 50$ & $15.13 \pm 2.22^{++}$ & $39.74 \pm 5.15^{++}$ & $42.52 \pm 3.68$ \\
\hline 7 & $A A-F S 50$ & $49.00 \pm 5.20$ & $62.81 \pm 6.04$ & $54.00 \pm 4.85$ \\
\hline 8 & $A A-P S 50-M T X$ & $38.06 \pm 6.75$ & $53.43 \pm 5.10$ & $47.03 \pm 2.47$ \\
\hline 9 & $A A-F S 50-M T X$ & $17.04 \pm 5.14^{++}$ & $54.77 \pm 7.70$ & $49.03 \pm 6.25$ \\
\hline
\end{tabular}

HC - control group, AA - adjuvant arthritis group, AA-MTX - adjuvant arthritis group administered Methotrexate $0.3 \mathrm{mg} / \mathrm{kg}$ twice a week, AA-PS5/AA-FS5 - adjuvant arthritis group administered PS/FS at dose of $5 \mathrm{mg} / \mathrm{kg}$, AA-PS50/AA-FS50 - adjuvant arthritis group administered PS/FS at dose of $50 \mathrm{mg} / \mathrm{kg}, \mathrm{AA}-\mathrm{PS} 50+\mathrm{MTX}$ and AA-FS50+MTX - adjuvant arthritis group administered PS or FS $(50 \mathrm{mg} / \mathrm{kg})$ and Methotrexate $0.3 \mathrm{mg} / \mathrm{kg}$ twice a week. Results are expressed as mean \pm SEM, $\mathrm{n}=8-10$. Significant difference: $* * \mathrm{p}<0.01$ vs. $\mathrm{HC}^{++} \mathrm{p}<0.01$ vs. $\mathrm{AA}$.

Table 3. Effect of PS, FS and MTX administered alone or in combination on the activity of $\gamma$-glutamyltransferase (GGT) in joint and spleen on the experimental day 28.

\begin{tabular}{lcc}
$\begin{array}{l}\text { Activity of GGT } \\
\text { [nmol } \\
\text { p-nitroaniline/ } \\
\text { min/g of tissue] }\end{array}$ & Joint & Spleen \\
\hline HC & & \\
$A A$ & $14.53 \pm 0.59$ & $14.55 \pm 2.30$ \\
$A A-M T X$ & $21.17 \pm 1.34^{* *}$ & $50.95 \pm 2.33^{* *}$ \\
$A A-P S 5$ & $18.77 \pm 1.10$ & $44.81 \pm 4.30$ \\
$A A-F S 5$ & $18.78 \pm 1.41$ & $53.82 \pm 2.38$ \\
$A A-P S 50$ & $20.35 \pm 2.13$ & $54.97 \pm 2.83$ \\
$A A-F S 50$ & $18.04 \pm 0.94$ & $55.38 \pm 3.56$ \\
$A A-P S 50-M T X$ & $18.34 \pm 0.80$ & $51.30 \pm 3.15$ \\
$A A-F S 50-M T X$ & $18.04 \pm 1.16$ & $51.85 \pm 2.43$ \\
& $18.77 \pm 1.11$ & $44.99 \pm 5.16$ \\
\hline
\end{tabular}

HC - control group, AA - adjuvant arthritis group, AA-MTX adjuvant arthritis group administered Methotrexate $0.3 \mathrm{mg} / \mathrm{kg}$ twice a week, AA-PS5/AA-FS5 - adjuvant arthritis group administered $\mathrm{PS} / \mathrm{FS}$ at dose of $5 \mathrm{mg} / \mathrm{kg}, \mathrm{AA}-\mathrm{PS} 50 / \mathrm{AA}-\mathrm{FS} 50-$ adjuvant arthritis group administered PS/FS at dose of $50 \mathrm{mg} / \mathrm{kg}$, AA-PS50+MTX and AA-FS50+MTX - adjuvant arthritis group administered PS or FS $(50 \mathrm{mg} / \mathrm{kg})$ and Methotrexate $0.3 \mathrm{mg} / \mathrm{kg}$ twice a week. Results are expressed as mean \pm SEM, $n=8-10$. Significant difference: $* * p<0.01$ AA vs. HC

without statistical significance (Table 3). Application of PS and FS did not have such significant impact; however, application of PS in higher dose $(50 \mathrm{mg} / \mathrm{kg})$ showed the most potent effect in joint and FS in higher dose $(50 \mathrm{mg} / \mathrm{kg})$ showed the most potent effect in spleen tissue.

\section{Interleukin-17A in plasma}

The level of IL-17A in untreated AA group increased approximately 5.24 times and was highly significant when compared to a group of healthy control animals on day $14(* * p<0.01$ AA vs. HC, Fig. 3$)$. This trend was also observed on day 21 and 28, where the levels of IL-17A were increased in untreated AA group comparing to $\mathrm{HC}$ but without statistical significance.

On day 14 in the group treated with MTX alone the plasmatic levels of this cytokine decreased highly significant comparing to untreated AA group $(++\mathrm{p}<0.01$ AA+MTX vs. AA); however, without significant effect on days 21 and 28.

Further, in the group of animals administered with PS alone in higher dose $(50 \mathrm{mg} / \mathrm{kg})$ the level of IL-17A was significantly decreased on day $14(+\mathrm{p}<0.05$ AA + PS50 vs. AA) and remarkably decreased on days 21 and 28. This effect of PS50 administration alone was comparable with the effect of MTX monotherapy. On day 14, the combination treatment of FS50 and MTX significantly reduced the plasmatic levels of IL-17A compared to the untreated AA group $(+\mathrm{p}<0.05$ AA-FS50+MTX vs. AA, Fig. 3) and not significantly during next following experimental days 21 and 28 . 


\section{Discussion}

Adjuvant arthritis (AA) is one of animal models widely used to study the mechanisms of active substances for preclinical testing of potential anti-inflammatory drugs (van Eden et al. 1996, Poništ et al. 2015). In the present study, we used AA to test anti-inflammatory properties of herbal preparation with code name PS-551 (PS) administered alone and in combination with Methotrexate (MTX). Then we compared the activity of PS with active substance of herbal para-medical product Fatsiphloginum $^{\mathrm{TM}}$ (FS). To evaluate the effectiveness of the substances tested, MTX was chosen as the treatment standard. In our previous experiments, MTX has been established as a good tool to evaluate the efficacy of experimental treatments (Bauerova et al. 2015, Drafi et al. 2012). Moreover, MTX is the most popular substance used worldwide as either in monotherapy or in combination with other drugs for the effective therapy of autoimmune disease (ACR 2002). The mechanism of action by which MTX exerts its anti-inflammatory and immunosuppressive effects were investigated according to the hypothesis that MTX exerts its effects via the production of reactive oxygen species (Phillips et al. 2003).

The substances tested (PS and FS) were obtained at the IPK from the plant Fatsia japonica cultivated in Georgia. Acute toxicity studies were not conducted with the purified extract in this study as the safety has been established up to $7,440 \mathrm{mg} / \mathrm{kg}$ by toxicological experiment (data not published). Two doses $5 \mathrm{mg} / \mathrm{kg}$ and $50 \mathrm{mg} / \mathrm{kg}$ were selected for PS and FS based on preliminary researches which have showed better response for doses above $5 \mathrm{mg} / \mathrm{kg}$ for anti-inflammatory activity.

In the AA model, systemic inflammation is manifested in increased hind paw volume, arthritic score and body weight loss. These parameters start to develop from day 10 after single intradermal injection of suspension of heat-inactivated Mycobacterium butyricum in incomplete Freund's adjuvant at the base of the tail (Bauerova et al. 2008b). In our experiment, we observed less body weight gain of untreated AA rats compared to healthy control rats, because of cachexia caused by autoimmune processes (Fig. 1). The previous experiments reported that basic parameters, such as HPV and body weight, became markedly worsened due to arthritis and were efficiently decreased by administration of substances with anti-oxidative and/or anti-inflammatory properties (Bauerova et al. 2008a, Bauerova et al. 2008b, Bauerova et al. 2009). When PS was administered at the dose of $50 \mathrm{mg} / \mathrm{kg}$ daily in monotherapy, it did not affected these parameters (HPV, CBW, arthritic score) in comparison to untreated AA animals and for administration of FS it was a similar situation (Fig. 1, Fig. 2, Table 2). The combination of PS and FS on day 14 was as effective as MTX alone in the following parameters CBW, HPV, and particularly the arthritic score.

AA is not only an experimental model of polyarthritis, but it also induces pathological changes in a variety of other tissues. Studies have shown that in the course of AA not only joints with obvious signs of inflammation, but also visceral organs may be affected by the pathological process (Bevaart et al. 2010).

GGT is an important component of inflammatory processes since its activity is closely connected with the overall antioxidant status of the organism. Elevated expression and activity of GGT in joint tissue is a good marker for synovial inflammation, thus molecules able to reduce the activity of GGT could be promising in therapy. The activity of GGT is considered as a reliable biochemical merit of inflammation and oxidative stress; its increased action in organs such as spleen and joint is believed to be a good indicator of AA development at the systemic and local level (Bauerova et al. 2006).

In our study, we observed increased activity of GGT in joint tissues and also in the spleen in untreated animals with induced AA. The activity of GGT was measured in the tissue homogenates of joint and spleen on experimental day 28 (Table 3). Administration of MTX led to slightly decreased values of GGT activity in the spleen and joint. This effect of MTX was reported also in previous experiments with a similar experimental design and setting (Bauerova et al. 2010, Drafi et al. 2012, Feketeova et al. 2012). The results of GGT activity measured in tissues of spleen and joint tissue after treatment with both tested compounds were not significantly affected. For GGT activity in spleen we observed that the combination of FS in dose $50 \mathrm{mg} / \mathrm{kg}$ and MTX was more potent than PS. However, in monotherapy PS in dose $50 \mathrm{mg} / \mathrm{kg}$ decreased the activity of GGT on day 28 in joint tissue homogenate (Table 3 ).

Previously, we have shown a good correlation between the GGT activity in joint tissue and HPV of arthritic animals (Bauerova et al. 2006). Similarly, as it is shown on Table 3, our measurements are in a good agreement with changes in HPV (Table 2). 
In recent years, many researchers have focused on imbalances within the immune system to explain the therapy of rheumatoid arthritis DMARDs (Disease Modifying Anti-rheumatic Drugs), including methotrexate. T-helper cells and their cytokines are important factors in regulating immune balance. Interferon- $\gamma$ (IFN- $\gamma$ ), interleukin-4 (IL-4), and interleukin-17A (IL-17A) represent the hallmarks for Th1, Th2, and Th17 cells, respectively (Mosmann et al. 1989, Ivanov et al. 2006, Mucida et al. 2007, Bettelli et al. 2008). MTX has been found to influence cytokine production and inhibits the up-regulations of IL-17A in the co-culture of T cells and fibroblasts (Miranda-Carus et al. 2004). Hou et al. (2011) hypothesized that MTX could ameliorate pristane-induced arthritis (PIA) by regulating immune balance. Arthritis in Dark agouti (DA) rats was induced by pristane and then treated with MTX. The authors studied the arthritis severity macroscopically and microscopically, and measured the gene expressions of IFN- $\gamma$, IL-4, IL-17A, transforming growth factor $\beta$, and tumor necrosis factor- $\alpha$ in the rat spleens. The authors have found that MTX can reduce the arthritis severity and decrease the mRNA expressions of IFN- $\gamma$ and IL-17A in pristane-induced arthritis of rats. In our study, we also decided to investigate the effect of our substances on the level of IL-17A in plasma during the development of AA. Significantly elevated plasmatic levels of this interleukin were detected on day 14, 21 and 28. One of the mechanisms of MTX anti-rheumatic activity can be explained by its ability to inhibit the production of pro-inflammatory cytokine - IL-17 in AA and RA (Ganesan and Rasool 2017). Signs of the onset of AA are followed by an acute intra-articular elevation of IL-17A, what probably means that IL-17A is more involved in the progression of the disease than in its early phase (Bush et al. 2001, Stolina et al. 2009). In our study, PS at higher concentration $(50 \mathrm{mg} / \mathrm{kg})$ significantly decreased the level of IL-17A on day 14. This effect was comparable with MTX treatment, which was highly significant on day 14 (Fig. 3). We hypothesize, that the effect of PS in higher dose towards IL-17A level in plasma on day 14 could be explained also by possible anti-inflammatory active property of the active substances - triterpene saponins, mostly derivatives of hederagenin and oleanic acid. Similarly to hederagenin molecule (hederagenin is the aglycone part of numerous saponins, e.g. $\alpha$-hederin) beneficial effect of $\alpha$-hederin (a water-soluble pentacyclic triterpenoid saponin) in ovalbumin-sensitized rats was described, suggesting that $\alpha$-hederin affects the IL-17 secretion pathways, altering miRNA-133a expression (Ebrahimi et al. 2016). To support our hypothesis of the possible effect of terpenes, it was described, that synthetic triterpenoids also inhibit IL-17 and could improve autoimmune disease in mice (Fitzpatrick et al. 2014). Moreover, it was also demonstrated, that oleanic acid (one of the component of PS-551) treatment inhibits dextran sodium sulfate-induced colitis, thus the induced expression of tumor necrosis factor- $\alpha$, interleukin- $1 \beta$, and IL-17 in vivo. Oleanic acid also inhibited the activation of $\mathrm{NF}-\kappa \mathrm{B}$ and expression of proinflammatory cytokines in LPS-stimulated peritoneal macrophages in vitro. These findings suggest that oleanic acid may ameliorate inflammatory diseases such as colitis by inhibiting Th17 cell differentiation and increasing T-reg cell differentiation (Kang et al. 2015). These triterpene saponins were previously described to have antiinflammatory activities (Kemertelidze et al. 2001, Shalamberidze et al. 1998). Our results indicate that PS-551 in higher doses in monotherapy could prevent systemic inflammation partly through blocking the production of IL-17 in acute stage of inflammation.

\section{Conclusions}

Based on the results of current study it can be concluded that PS and FS administrated in dose of $5 \mathrm{mg} / \mathrm{kg}$ alone daily did not affect the parameters selected during the whole experiment. On the other hand, PS in its highly pure composition administrated alone in dose $50 \mathrm{mg} / \mathrm{kg}$ daily had shown a therapeutic effect on the plasmatic level of IL-17A in early phases of AA. However, FS administrated alone in dose $50 \mathrm{mg} / \mathrm{kg}$ daily had no significant effect on HPV and arthritic score. The present study showed that generally FS has higher antiarthritic activity in comparison to PS. In this study, we also tested the novel combination of the active substance of Fatsiphloginum ${ }^{\mathrm{TM}}$ as well as the extract PS-551 with MTX on the AA model. The combinations of PS and FS in higher doses improved its effect together with MTX in early stages of AA, which was demonstrated on the change of body weight, arthritic score and change of HPV. Moreover, FS in dose $50 \mathrm{mg} / \mathrm{kg}$ daily in combination with MTX significantly showed its antiinflammatory properties on plasmatic level of IL-17A. Our findings indicate that in experimental model of AA higher doses than $50 \mathrm{mg} / \mathrm{kg}$ are required to achieve a better anti-rheumatic effect. To have a more explicit understanding of anti-inflammatory and anti-arthritic 
activities of substances derived from Fatsia japonica further experimental studies with broader spectrum of immunological parameters will be required.

\section{Conflict of Interest}

There is no conflict of interest.

\section{Acknowledgements}

This study was supported by grants: VEGA 2/0044/15, VEGA 2/0115/19, APVV-15-0308. The research was also supported by National Scholarship Programme of the Slovak Republic (NSP), the grant was awarded to Lia Tsiklauri. For technical support, we would like to thank to Ing. Danica Mihalova and Janka Urgosova.

\section{References}

ACR (American College of Rheumatology) Subcommittee on Rheumatoid Arthritis Guidelines: Guidelines for the management of rheumatoid arthritis: 2002 Update. Arthritis Rheum 46: 328-346, 2002.

BAUEROVA K, PONIST S, ONDREJICKOVA O, KOMENDOVA D, MIHALOVA D: Association between tissue gamma-glutamyl-transferase and clinical markers of adjuvant arthritisin Lewis rats. Neuroendocrinol Lett 27 : 172-175, 2006.

BAUEROVA K, KUCHARSKA J, PONIST S, GVOZDJAKOVA A: Coenzyme Q10 supplementation in adjuvant arthritis (pre-clinical study). In: Mitochondrial Medicine: Mitochodrial Metabolism, Diseases, Diagnosis and Therapy. GVOZDJAKOVA A (ed.), Springer Verlak, Berlin, 2008a, pp 340-342.

BAUEROVA K, PONIST S, NAVAROVA J, DUBNICKOVA M, PAULOVICOVA E, PAJTINKA M, KOGAN G, MIHALOVA D: Glucomannan in prevention of oxidative stress and inflammation occurring in adjuvant arthritis. Neuroendocrinol Lett 29: 691-696, 2008b.

BAUEROVA K, PAULOVICOVA E, MIHALOVA D, SVIK K, PONIST S: Study of new ways of supplementary and combinatory therapy of rheumatoid arthritis with immunomodulators. Glucomannan and Imunoglukan in adjuvant arthritis. Toxicol Ind Health 25: 329-335, 2009.

BAUEROVA K, PAUlovicova E, MiHAlova D, DRAFi F, STROSOVA M, MASCIA C, BIASI F, ROVENSKY J, KUCHARSKA J, GVOZDJAKOVA A, PONIST S: Combined methotrexate and coenzyme Q10 therapy in adjuvant-induced arthritis evaluated using parameters of inflammation and oxidative stress. Acta Biochim Pol 57: 347-354, 2010.

BAUEROVÁ K, PONIŠT S, MIHALOVÁ D, DRÁFI F, KUNCÍROVÁ V: Utilization of adjuvant arthritis model for evaluation of new approaches in rheumatoid arthritis therapy focused on regulation of immune processes and oxidative stress. Interdiscip Toxicol 4: 33-39, 2011.

BAUEROVA K, ACQUAVIVA A, PONIST S, GARDI C, VECCHIO D, DRAFI F, AREZZINI B, BEZAKOVA L, KUNCIROVA V, MIHALOVA D, NOSAL R: Markers of inflammation and oxidative stress studied in adjuvant-induced arthritis in the rat on systemic and local level affected by pinosylvin and methotrexate and their combination. Autoimmunity 48: 46-56, 2015.

BENDELE AM: Animal models of rheumatoid arthritis. J Musculoskelet Neuronal Interact 1: 377-385, 2001.

BETTELI E, KORN T, OUKKA M, KUCHROO VK: Induction and effector functions of TH17 cells. Nature 453: 1051-1057, 2008.

BEVAART L, VERVOORDELDONK MJ, TAK PP: Evaluation of therapeutic targets in animal models of arthritis: how does it relate to rheumatoid arthritis? Arthritis Rheum 62: 2192-2205, 2010.

BUSH KA, WALKER JS, LEE CS, KIRKHAM BW: Cytokine expression and synovial pathology in the initiation and spontaneous resolution phases of adjuvant arthritis: interleukin-17 expression is upregulated in early disease. Clin Exp Immunol 123: 487-495, 2001.

CHEN L, DENG H, CUI H, FANG J, ZUO Z, DENG J, LI Y, WANG X, ZHAO L: Inflammatory responses and inflammation-associated diseases in organs. Oncotarget 9: 7204-7218, 2017.

DESAI S, DESAI DG, KAUR H: Saponins and their biological activities. Pharma Times 41: 13-16, 2009.

DRAFI F, BAUEROVA K, KUNCIROVA V, PONIST S, MIHALOVA D, FEDOROVA T, HARMATHA J, NOSAL R: Pharmacological influence on processes of adjuvant arthritis: effect of the combination of an antioxidant active substance with methotrexate. Interdiscip Toxicol 5: 84-91, 2012. 
EBRAHIMI H, FALLAHI M, KHAMANEH AM, EBRAHIMI SAADATLOU MA, SAADAT S, KEYHANMANESH R: Effect of $\alpha$-hederin on IL-2 and IL-17 mRNA and miRNA-133a levels in lungs of ovalbumin-sensitized male rats. Drug Dev Res 77: 87-93, 2016.

FEKETEOVA L, JANČOVA P, MORAVCOVA P, JANEGOVA A, BAUEROVA K, PONIŠT S, MIHALOVA D, JANEGA P, BABAL P: Effect of methotrexate on inflammatory cells redistribution in experimental adjuvant arthritis. Rheumatol Int 32: 3517-3523, 2012.

FITZPATRICK LR, STONESIFER E, SMALL JS, LIBY KT: The synthetic triterpenoid (CDDO-Im) inhibits STAT3, as well as IL-17, and improves DSS-induced colitis in mice. Inflammopharmacology 22: 341-349, 2014.

FOURNIER C: Where do T cells stand in rheumatoid arthritis? Joint Bone Spine 72: 527-532, 2005.

GANESAN R, RASOOL M: Interleukin 17 regulates SHP-2 and IL-17RA/STAT-3 dependent Cyr61, IL-23 and GM-CSF expression and RANKL mediated osteoclastogenesis by fibroblast-like synoviocytes in rheumatoid arthritis. Mol Immunol 9: 134-144, 2017.

GETIA M, MSHVILDADZE V, PICHETTE A, DEKANOSIDZE G, KEMOKLIDZE Z: Development of analytical procedure for the quantification of "Fatsiflogin". J Pharmacy 7: 96-99, 2017.

HAZLEWOOD GS, BARNABE C, TOMLINSON G, MARSHALL D, DEVOE D, BOMBARDIER C: Methotrexate monotherapy and methotrexate combination therapy with traditional and biologic disease modifying antirheumatic drugs for rheumatoid arthritis: abridged Cochrane systematic review and network meta-analysis. BMJ 353: i1777, 2016.

HOU W, MENG L, WEN Y, ZHU W, JIANG C, HE X, ZHOU Y, LU S: Methotrexate ameliorates pristane-induced arthritis by decreasing IFN- $\gamma$ and IL-17A expressions. J Zhejiang Univ Sci B 12: 40-46, 2011.

IVANOV II, MCKENZIE BS, ZHOU L, TADOKORO CE, LEPELLEY A, LAFAILLE JJ, CUA DJ, LITTMAN DR: The orphan nuclear receptor ROR $\gamma t$ directs the differentiation program of proinflammatory IL-17+ T helper cells. Cell 126: 1121-1133, 2006.

KANG GD, LIM S, KIM DH: Oleanolic acid ameliorates dextran sodium sulfate-induced colitis in mice by restoring the balance of Th17/Treg cells and inhibiting NF-kB signaling pathway. Int Immunopharmacol 29: 393-400, 2015.

KEMERTELIDZE E, KEMOKLIDZE Z, DEKANOSIDZE G, BEREZNYAKOVA A: Triterpene glycosides of Fatsia japonica cultivated in Georgia and their pharmacological activity. Pharmaceutic Chem J 35: 229-432, 2001.

KOZIOLOVÁ E, VENCLÍKOVÁ K, ETRYCH T: Polymer-drug conjugates in inflammation treatment. Physiol Res 67 (Suppl 2): S281-S292, 2018.

MAROON JC, BOST JW, MAROON A: Natural anti-inflammatory agents for pain relief. Surg Neurol Int 1: 80, 2010.

MESGARZADEH I, AKBARZADEH AR, RAHIMI R: Surface active properties of solvent extracted Panax ginseng saponin based surfactants. J Surfact Deterg 20: 609-614, 2017.

MIRANDA-CARUS ME, BALSA A, BENITO-MIGUEL M, PEREZ DE AYALA C, MARTIN-MOLA E: IL-15 and the initiation of cell contact-dependent synovial fibroblast-T lymphocyte cross-talk in rheumatoid arthritis: effect of methotrexate. J Immunol 173: 1463-1476, 2004.

MOSMANN TR, COFFMAN RL: TH1 and TH2 cells: different patterns of lymphokine secretion lead to different functional properties. Annu Rev Immunol 7: 145-173, 1989.

MUCIDA D, PARK Y, KIM G, TUROVSKAYA O, SCOTT I, KRONENBERG M, CHEROUTRE H: Reciprocal TH17 and regulatory T cell differentiation mediated by retinoic acid. Science 317: 256-260, 2007.

ONDREJICKOVA O, ZIEGELHOEFFER A, GABAUER I, SOTNIKOVA R, STYK J, GIBALA P, SEDLAK J, HORAKOVA L: Evaluation of ischemia-reperfusion injury by malondialdehyde, glutathione and gammaglutamyl transpeptidase: lack of specific local effects in diverse parts of the dog heart following acute coronary occlusion. Cardioscience 4: 225-230, 1993.

ORLOWSKI M, MEISTER A: The gamma-glutamyl cycle: a possible transport system for amino acids. Proc Natl Acad Sci U S A 67: 1248-1255, 1970.

PHILLIPS DC, WOOLLARD KJ, GRIFFITHS HR: The anti-inflammatory actions of methotrexate are critically dependent upon the production of reactive oxygen species. Br J Pharmacol 138: 501-511, 2003. 
PONIŠT S, SLOVÁK L, KUNCÍROVÁ V, FEDOROVA T, LOGVINENKO A, MUZYCHUK O, MIHALOVÁ D, BAUEROVÁ K: Inhibition of oxidative stress in brain during rat adjuvant arthritis by carnosine, trolox and novel trolox-carnosine. Physiol Res 64 (Suppl 4): S489-S496, 2015.

SGLUNDA O, MANN HF, HULEJOVÁ H, PECHA O, PLEŠTILOVÁ L, RŮŽIČKOVÁ O, FOJTÍKOVÁ M, SLÉGLOVÁ O, FOREJTOVÁ S, PAVELKA K, VENCOVSKÝ J, SENOLT L: Decrease in serum interleukin-21 levels is associated with disease activity improvement in patients with recent-onset rheumatoid arthritis. Physiol Res 63: 475-481, 2014.

SHALAMBERIDZE L, TSITLANADZE V, KEMERTELIDZE E, KARTVELSHVILI E: Fatsiphlogin® - new plant origin preparation in therapy of RA (Rheumatoid Arthritis). Ross Revmatol 1: 43-45, 1998.

SMOLEN SJ, LANDEWÉ R, BREEDVELD CF, DOUGADOS M, EMERY P, GAUJOUX-VIALA C, GORTER S, KNEVEL R, NAM J, SCHOELS M, ALETAHA D, BUCH M, GOSSEC L, HUIZINGA T, BIJLSMA JW, BURMESTER G, COMBE B, CUTOLO M, GABAY C, GOMEZ-REINO J, KOULOUMAS M, KVIEN TK, MARTIN-MOLA E, MCINNES I, PAVELKA K, VAN RIEL P, SCHOLTE M, SCOTT DL, SOKKA T, VALESINI G, VAN VOLLENHOVEN R, WINTHROP KL, WONG J, ZINK A, VAN DER HEIJDE D: EULAR recommendations for the management of rheumatoid arthritis with synthetic and biological diseasemodifying antirheumatic drugs. Ann Rheum Dis 69: 964-975, 2010.

SPARG SG, LIGHT ME, STADEN J: Biological activities and distribution of plant saponins. Ethnopharmacology 94 : 219-243, 2004.

STOLINA M, BOLON B, MIDDLETON S, DWYER D, BROWN H, DURYEA D, ZHU L, ROHNER A, PRETORIUS J, KOSTENUIK P, FEIGE U, ZACK D: The evolving systemic and local biomarker milieu at different stages of disease progression in rat adjuvant-induced arthritis. J Clin Immunol 29: 158-174, 2009.

SULTANA N, SAIFY ZS: Naturally occurring and synthetic agents as potential anti-inflammatory and immunomodulants. Antiinflamm Antiallergy Agents Med Chem 11: 3-19, 2012.

TSIKLAURI L, DELATTRE L, DEKANOSIDZE G, SULAKVELIDZE TS, KEMOKLIDZE Z, KEMERTELIDZE E: Fatsiflogin tablets: composition design and technology development. Farmacia 4: 36-39, 2004.

VAN EDEN W, WAGENAAR-HILBERS JP, WAUBEN MH: Adjuvant arthritis in the rat. Curr Protoc Immunol 19: 15.4.1-15.4.8, 1996.

WALTHELM U, DITTRICH K, GELBRICH G, SCHÖPKE T: Effects of saponins on the water solubility of different model compounds. Plantamedica 67: 49-54, 2001.

WANG H, GAO J, KOU J, ZHU D, YU B: Anti-inflammatory activities of triterpenoid saponins from Polygala japonica. Phytomedicine 15: 321-326, 2008.

WU YQ, WANG YL, LEI TZ, XIA YQ: The solubilization capability of polycyclic aromatic hydrocarbons enhanced by biosurfactant saponin mixed with conventional chemical surfactants. Pet Sci Technol 32: 108-115, 2014. 